\title{
Anti-nociceptive and antioxidant activities of an aqueous leaf extract of Corchorus olitorius L. (Tiliaceae)
}

\author{
A. BOYE ${ }^{1}$, V.Y.A. BARKU ${ }^{2 *}$, P. AMOATENG ${ }^{3}$ and L.A. MBROH ${ }^{1}$ \\ ${ }^{l}$ Department of Medical Laboratory, University of Cape Coast, Cape Coast, Ghana. \\ ${ }^{2}$ Department of Chemistry, University of Cape Coast, Cape Coast, Ghana. \\ ${ }^{3}$ Department of Pharmacology and Toxicology, School of Pharmacy, \\ University of Ghana, Legon, Accra, Ghana. \\ *Corresponding author ; E-mail: vbarku@ucc.edu.gh; atsubarku@yahoo.com
}

\begin{abstract}
A preliminary study had shown that $C$. olitorius has analgesic activity possibly mediated through opioidergic pathway. The study was a follow up work to evaluate the anti-nociceptive effects and other possible mechanisms of action of an aqueous leaf extract of $C$. olitorius (COE) using formalin-induced nociception test. COE was screened for its analgesic, and antioxidant activities. The anti-nociceptive effect of $\operatorname{COE}\left(3 \times 10^{-2}, 1 \times 10^{-1}\right.$ and $3 \times 10^{-1} \mathrm{~g} \mathrm{~kg}^{-1}$, p.o $)$, and morphine $\left(1 \times 10^{-3}, 3 \times 10^{-3}\right.$ and $1 \times 10^{-2} \mathrm{gkg}^{-1}$, i.p. $)$ were evaluated using the formalin-induced nociception test. The study showed that $C$. olitorius has analgesic activity possibly mediated through opioidergic pathway. COE produced significant $(\mathrm{P}<0.05)$ dose-dependent antinociceptive effects similar to morphine in both phases of formalin-induced nociception. The extract showed free radical scavenging properties and different phyto-constituents such as alkaloids, flavonoids, saponins, cardiac glycosides, tannins, anthraquinones and terpenoids were identified. COE has both central and peripheral anti-nociceptive effects mediated through opioidergic receptor activation and also partly through ATP-sensitive $\mathrm{K}^{+}$channel activation systems. The findings confirms earlier reports, and further shows that $C$. olitorius produces anti-nociception by interrupting many pain processing pathways. Results further suggest that the extract (COE) might possess some chemical constituents that are responsible for the analgesic and the antioxidant activities.
\end{abstract}

(C) 2014 International Formulae Group. All rights reserved.

Keywords: Naloxone, glibenclamide, morphine, nociception, DPPH, formalin test.

\section{INTRODUCTION}

Corchorius olitorius is an annual herb, commonly known among the Hausa, Dagbani, Akan and Ga tribes of Ghana as "ayoyo" and it belongs to the family Tiliaceae. It is used as an herbal medicine and is eaten as a vegetable by local people in various parts of the world, including Ghana, Egypt, India, the Philippines, and Malaysia (Zeghichi et al., 2003).
The leaves of $C$. olitorius are reported to be used traditionally as a demulcent, diuretic, febrifuge, and tonic, and also in the treatment of pain and fever (Zeghichi et al., 2003).

Due to the usefulness of $C$. olitorius as a vegetable (food) and also as a herbal remedy by many traditions across Africa and beyond, many workers have explored its pharmacological properties in order to 
scientifically explain some of its reported local uses. Prominent among these workers is Zakaria et al. (2005) who had demonstrated that the aqueous leaf extract of $C$. olitorius (COE) possesses peripheral and central antinociceptive effect, which are both mediated, at least in part, via the opioid receptor stimulation using the abdominal constriction and hot plate tests in mice. In as much as we appreciate their findings, we however think that the abdominal constriction and hot plate models they used were not sensitive enough and also lack specificity to adequately show the anti-nociceptive effect of $C$. olitorius and its possible site/mechanism of action. It is against this background that we sought to investigate the anti-nociceptive effect of COE and its possible site/mechanism of action by using the rodent formalin-induced nociception test. The rodent formalin test has been shown to be very predictive of acute pain (Le-Bars et al., 2001) and thus a valid model (Vasconcelos et al., 2003; Vissers et al., 2003) and a well characterized and accepted method in pre-clinical screening of analgesics (Vissers et al., 2003). One other important feature of the rodent formalin test is that two principally different stimuli are employed in the same test. It is for this reason that the rodent formalin test has been regarded as being a more satisfactory model for studying preclinical pain than the abdominal constriction and hot plate tests (Zouikr et al., 2013). The study was therefore designed to confirm the anti-nociceptive effect and investigate the possible mechanism of action of $C$. olitorius leaf extract through the rodent formalininduced nociception test. Antioxidant activities are said to be contributory factors to the medicinal properties of plants. Consequently, DPPH radical scavenging assay which has widespread use in antioxidant screening because, it is a very simple and rapid test that needs only a UV-vis spectrophotometer to perform (Ronald et al., 2005), was used to determine the antioxidant activity of the plant extract.

\section{MATERIALS AND METHODS \\ Drugs and chemicals}

Drugs and chemicals used in the study included the following: Morphine hydrochloride (Phyto-Riker, Accra, Ghana), naloxone (Troge Medical Gmbh, Hamburg, Germany) and glibenclamide $\left(\right.$ Daonil $^{\circledR}$, Sanofi-Aventis, Guildford, UK), amd buffered formalin (BDH, Poole, England). All the chemicals were of analytical grade.

\section{Plant collection, identification and authentication \\ C. olitorius was collected from} Amamoma, a suburb of Cape Coast, Ghana in February, 2013. The plant was identified and authenticated by a pharmacognosist at the herbarium unit of the School of Biological Sciences, University of Cape Coast, where a voucher specimen (UCC/SBS/C173) was deposited.

\section{Preparation of aqueous leaf extract of $C$. olitorius}

Leaves of $C$. olitorius were washed with distilled water and then dried in Gallenkamp hot air oven (Oven 300 Plus Series, England) at $50{ }^{\circ} \mathrm{C}$ for five hours until fully dried. The dried leaves were then blended into a fine textured powder by using ablender (Chefman, England). A $500.0 \mathrm{~g}$ quantity of the blended leaves was mixed with $2 \mathrm{~L}$ of distilled water in a volumetric flask allowed to stay for 24 hours. The cold infusion mixture obtained was filtered using a muslin cloth and concentrated under reduced pressure in a Buchi Rotor Evaporator (Rotavapor, R-210, Switzerland). The resulting filtrate in a pre-weighed dry crucible was further evaporated to dryness by evaporation on a water bath. The percentage yield of the aqueous leaf extract of $C$. olitorius (COE) was $21.5 \%$.

\section{Phytochemical screening \\ COE was subjected to phytochemical screening using standard techniques of phytochemical analysis as described by}


Prashant et al. (2011) with some modification as described briefly below.

Alkaloid detection was carried out by extracting $0.5 \mathrm{~g}$ COE sample with $5 \mathrm{ml}$ methanol and $5 \mathrm{ml}$ of $2 \mathrm{M} \mathrm{HCl}$; and then reacting the filtrate with Meyer's and Wagner's reagents. The samples were scored positive on the basis of turbidity or precipitation. Flavonoids were tested for by heating $0.5 \mathrm{~g}$ COE sample with $10 \mathrm{ml}$ ethyl acetate over a steam bath $\left(40-50{ }^{\circ} \mathrm{C}\right)$ for 5 minutes; filtrate was treated with $1.0 \mathrm{ml}$ dilute ammonia. No yellow colouration demonstrated negative test for flavonoids while the vice versa demonstrates positive test. The presence of tannins was confirmed by diluting $1 \mathrm{ml}$ of the alcoholic extract with $2.0 \mathrm{ml}$ of distilled water, followed by addition of 3.0 drops of $5 \% \mathrm{FeCl}_{3}$ to the filtrate. Development of greenish blue colouration was taken as positive for the presence of tannins. Saponins were determined by boiling $0.5 \mathrm{~g}$ COE sample in $10.0 \mathrm{ml}$ distilled water for 15.0 minutes and after cooling, the extract was shaken vigorously to record froth formation. Cardiac glycosides were identified by extracting $0.5 \mathrm{~g}$ COE in $10.0 \mathrm{ml}$ methanol. Five $\mathrm{ml}$ of this methanolic extract was treated with $2.0 \mathrm{ml}$ glacial acetic acid containing 1.0 drop of $5 \% \mathrm{FeCl}_{3}$ solution. This solution was carefully transferred to surface of $1 \mathrm{ml}$ concentrated $\mathrm{H}_{2} \mathrm{SO}_{4}$. The formation of reddish brown ring at the junction of two liquids was indicative of cardenolides/cardiac glycosides. Terpenoids were identified by taking $0.5 \mathrm{~g}$ of the plant extract in $2 \mathrm{ml}$ of chloroform. Concentrated $\mathrm{H}_{2} \mathrm{SO}_{4}$ was added to form a layer. A reddish brown colouration of the interface indicated the presence of terpenoids.

\section{Scavenging activity against 1,1-diphenyl-2- picryl hydrazyl radical (DPPH)}

The extracts were screened for DPPH radical scavenging activity. DPPH radical scavenging activity was evaluated as described by Stankovic et al. (2010). The stock solution of the plant extract was prepared in methanol to achieve a concentration of $100 \mu \mathrm{g} \mathrm{ml}^{-1}$. Dilutions were made to obtain concentrations of $80 \mu \mathrm{g} \mathrm{ml}^{-1}$, $40 \mu \mathrm{g} \mathrm{ml}^{-1}$, and $20 \mu \mathrm{g} \mathrm{ml}^{-1}$. $1 \mathrm{ml}$ of each of the diluted solutions was mixed with $1.0 \mathrm{ml}$ of DPPH methanolic solution $\left(40 \mu \mathrm{g} \mathrm{ml}^{-1}\right)$. After 30 minutes in the darkness at room temperature $\left(23{ }^{\circ} \mathrm{C}\right)$, the absorbance was recorded at $517 \mathrm{~nm}$. The control sample contained all the reagents except the extract. All experiments were performed thrice and the results were averaged. Percent inhibition was calculated using the following expression:

$$
\% \text { inhibition }=\frac{\left(A_{\text {blank }}-A_{\text {sample }}\right) \times 100}{A_{\text {blank }}}
$$

Where $A_{\text {blank }}$ and $A_{\text {sample }}$ stand for absorption of the blank sample and absorption of tested extract solution respectively. $\mathrm{IC}_{50}$ value was estimated. $\mathrm{IC}_{50}$ value denotes the concentration of test, which is required to scavenge $50 \%$ of DPPH free radicals.

\section{Analgesic activity Animals}

Healthy four weeks old ICR mice (25$35 \mathrm{~g}$ ) of either sex were purchased from Noguchi Memorial Institute for Medical Research (NMIMR), University of Ghana, Legon, Accra, Ghana and maintained at the Animal Experimentation Department of same. The animals were housed in groups of 7.0 in stainless steel cages $(34 \times 47 \times 18 \mathrm{~cm})$ with soft wood shavings as bedding, fed with normal commercial pellet diet (GAFCO, Tema, Ghana), and were given water ad libitum. Animals were maintained under laboratory conditions (Temperature $24-28{ }^{\circ} \mathrm{C}$, Relative Humidity 60-70\% and $12 \mathrm{~h}$ lightdark cycle). All procedures and techniques used in the studies were in accordance with the National Institute of Health Guidelines for the Care and Use of Laboratory Animals (NIH, Department of Health and Human Services publication No. 85-23, revised 1985). The Departmental Ethics Committee approved the protocols for the study. 


\section{Formalin-induced nociception}

The formalin test was carried out as previously described by Khanavi et al. (2012) with some few modifications. Mice were randomly divided into seven groups of 5 mice each and treated as follows: COE $\left(3 \times 10^{-2}\right.$, $1 \times 10^{-1}$ and $3 \times 10^{-1} \mathrm{gkg}^{-1}$, p.o), morphine $\left(1 \times 10^{-3}, 3 \times 10^{-3}\right.$ and $1 \times 10^{-2} \mathrm{gkg}^{-1}$, i.p.) as positive control and formalin-treated group as negative control. Each animal was assigned and acclimatized to one of twenty Perplex test chambers $(15 \times 15 \times 15 \mathrm{~cm})$ for 30 minutes before the treatments. Morphine was given to mice 30 minutes and COE 1hour before the induction of nociceptive behaviours in the animals by a subcutaneous injection of $10 \mu \mathrm{L}$ of $5 \%$ formalin solution into the plantar tissues of the right hind paw. Animals were immediately returned individually into the testing chamber.

A mirror was placed at an angle of $45^{\circ}$ beneath the chambers to allow an unobstructed view of the hind paws. The nociceptive behaviours of each mouse was then captured for a period of 60 minutes with a camcorder (Everio $^{\mathrm{TM}}$ model GZ-MG1300, JVC, Tokyo, Japan) placed in front of the mirror.

In a separate experiment, the effects of naloxone $\left(2 \times 10^{-3} \mathrm{gkg}^{-1} i . p\right)$, an opioid receptor antagonist and glibenclamide $\left(8 \times 10^{-3} \mathrm{gkg}^{-}\right.$ ${ }^{1}$ p.o), an ATP-sensitive potassium channel blocker, on the anti-nociceptive effects of COE $\left(1 \times 10^{-1} \mathrm{gkg}^{-1}\right.$ p.o $)$ and morphine $\left(3 \times 10^{-}\right.$ ${ }^{3} \mathrm{gkg}^{-1}$ i.p) were investigated. Naloxone was administered 30 minutes before the administration of COE or morphine whilst glibenclamide was administered an hour before the administration of $\mathrm{COE}$ or morphine. Pain responses were scored for 60 minutes, starting immediately after formalin injection as previously described. A nociceptive score was determined for each 5 minutes time block by measuring the time spent in biting or licking of the injected paw (Hayashida et al., 2003). Behavioural responses were scored from the videotapes with the aid of the public domain software JWatcher ${ }^{\mathrm{TM}}$ Version 1.0 (University of California, Los Angeles, USA and Macquarie University, Sydney, Australia available at http:www.jwatcher.ucla.eu/). Average nociceptive score for each time block was calculated by multiplying the frequency and time spent in biting or licking. Data were expressed as the mean \pm s.e.m scores between 0-10 and 10-60 minutes after formalin injection.

\section{Statistical analysis}

Values were presented as Means \pm SEM. Significant differences in measured parameters between treatments were established either by; Two-way ANOVA followed by Bonferroni's post hoc test, or One-way ANOVA followed by Dunnett's Multiple Comparison post hoc test available in Graph Pad Prism for Windows Version 5.00 (Graph Pad software, San Diego, California, USA). A P $\leq 0.05$ was considered statistically significant for all analyses. The graphs were plotted using Sigma Plot Version 11 for windows (Systat Software Inc. Germany).

\section{RESULTS}

\section{Phytochemical screening}

Preliminary phytochemical screening of COE showed the presence of some phytocompounds. The result is shown in Table 1.

\section{Antioxidant activity \\ From the DPPH radical antioxidant test, both COE and ascorbic acid (Standard) caused a concentration dependent percentage increase in antioxidant activity (Table 2). However, at equipotent concentrations, ascorbic acid had a better antioxidant activity compared to COE (Table 2).}

\section{Formalin-induced nociception test}

In the formalin-induced nociception test, COE produced a dose-dependent anti- 
nociceptive effect comparable to morphine at least in phase II (Figure 1. Panels B \& D). Although both COE and morphine produced anti-nociceptive effects in phase $\mathrm{I}$, that of COE was not dose-dependent since it was only significant $(\mathrm{P}<0.05)$ at the highest dose (300 $\mathrm{mg} \mathrm{kg}^{-1}$ ) compared to morphine, which produced significant $(\mathrm{P}<0.0001)$ antinociceptive effects at all the doses (Figure 1. Panel B \& D). The observed anti-nociceptive effects of COE and morphine were not comparable to the vehicle treated group (Figure 1. Panels A \& C). Though COE produced anti-nociceptive effect comparable to morphine, it was however less potent (Table 3).

Glibenclamide, an ATP-sensitive $\mathrm{K}^{+}$ channel blocker significantly $(\mathrm{P}<0.05)$ inhibited the anti-nociceptive effects of $\mathrm{COE}$ and however had insignificant $(\mathrm{P}>0.05)$ effect on the anti-nociceptive effects of morphine in phase I of formalin-induced nociception (Figure 2A, left panel). Naloxone, a specific opioid receptor antagonist significantly $(\mathrm{P}<0.001)$ inhibited the antinociceptive effects of COE and morphine (Figure 2A, right panel).

Similarly, glibenclamide significantly ( $\mathrm{P}<0.0001 ; \mathrm{P}<0.001)$ inhibited the antinociceptive effects of $\mathrm{COE}$ and morphine respectively in phase II of formalin-induced nociception (Figure 2. B, left panel). Naloxone, like glibenclamide also significantly $(\mathrm{P}<0.0001 ; \mathrm{P}<0.001)$ inhibited the anti-nociceptive effects of $\mathrm{COE}$ and morphine respectively in phase II of formalininduced nociception (Figure 2. B, right panel).

Table 1: Phytocompounds detected in COE.

\begin{tabular}{lc}
\hline Phytocompound & Result \\
\hline Alkaloids & + \\
Terpenoids & + \\
Tannins & + \\
Flavonoids & + \\
Saponins & + \\
Cardiac glycosides & + \\
Anthraquinones & + \\
\hline \multicolumn{2}{c}{+ indicates presence }
\end{tabular}

Table 2: Antioxidant activities of COE compare with ascorbic acid as the standard.

\begin{tabular}{lcc}
\hline & \% Inhibition of DPPH free & radical activity \\
\hline Concentration $\left(\boldsymbol{\mu g ~ \mathbf { ~ m l } ^ { - 1 } )}\right.$ & COE & Ascorbic Acid \\
\hline $\mathbf{2 0}$ & $26.84 \pm 0.01$ & $94.61 \pm 2.52$ \\
$\mathbf{4 0}$ & $35.52 \pm 0.03$ & $99.10 \pm 0.52$ \\
$\mathbf{8 0}$ & $41.87 \pm 0.00$ & $99.64 \pm 0.08$ \\
$\mathbf{1 0 0}$ & $43.22 \pm 0.00$ & $99.94 \pm 0.03$ \\
$\mathbf{I C}_{\mathbf{5 0}}$ & $127.15 \mu \mathrm{g} \mathrm{ml}^{-1}$ & $7.39 \mu \mathrm{g} \mathrm{ml}^{-1}$ \\
\hline \multicolumn{2}{c}{ COE $=$ Aqueous leaf extract of $C$. olitorius $; \mathrm{IC}_{50}=$ the concentration of test, which is required to scavenge $50 \%$} \\
\multicolumn{2}{l}{ of DPPH free radicals. }
\end{tabular}


Table 3: $\mathrm{ED}_{50}$ values for $\mathrm{COE}$ and morphine in the formalin test.

\begin{tabular}{lcc}
\hline \multirow{2}{*}{ Drug } & \multicolumn{2}{c}{ ED $_{\mathbf{5 0}}(\mathbf{m g} / \mathbf{k g})$} \\
\cline { 2 - 3 } & Phase 1 & Phase 2 \\
\hline COE & $282.50 \pm 23.15$ & $30.51 \pm 8.54$ \\
Morphine & $5.17 \pm 12.36$ & $6.60 \pm 19.36$ \\
\hline
\end{tabular}

$\mathrm{COE}=$ Aqueous leaf extract of $C$. olitorius $; \mathrm{ED}_{50}=$ Effective the dose of a drug that produce $50 \%$ of the desired effect.
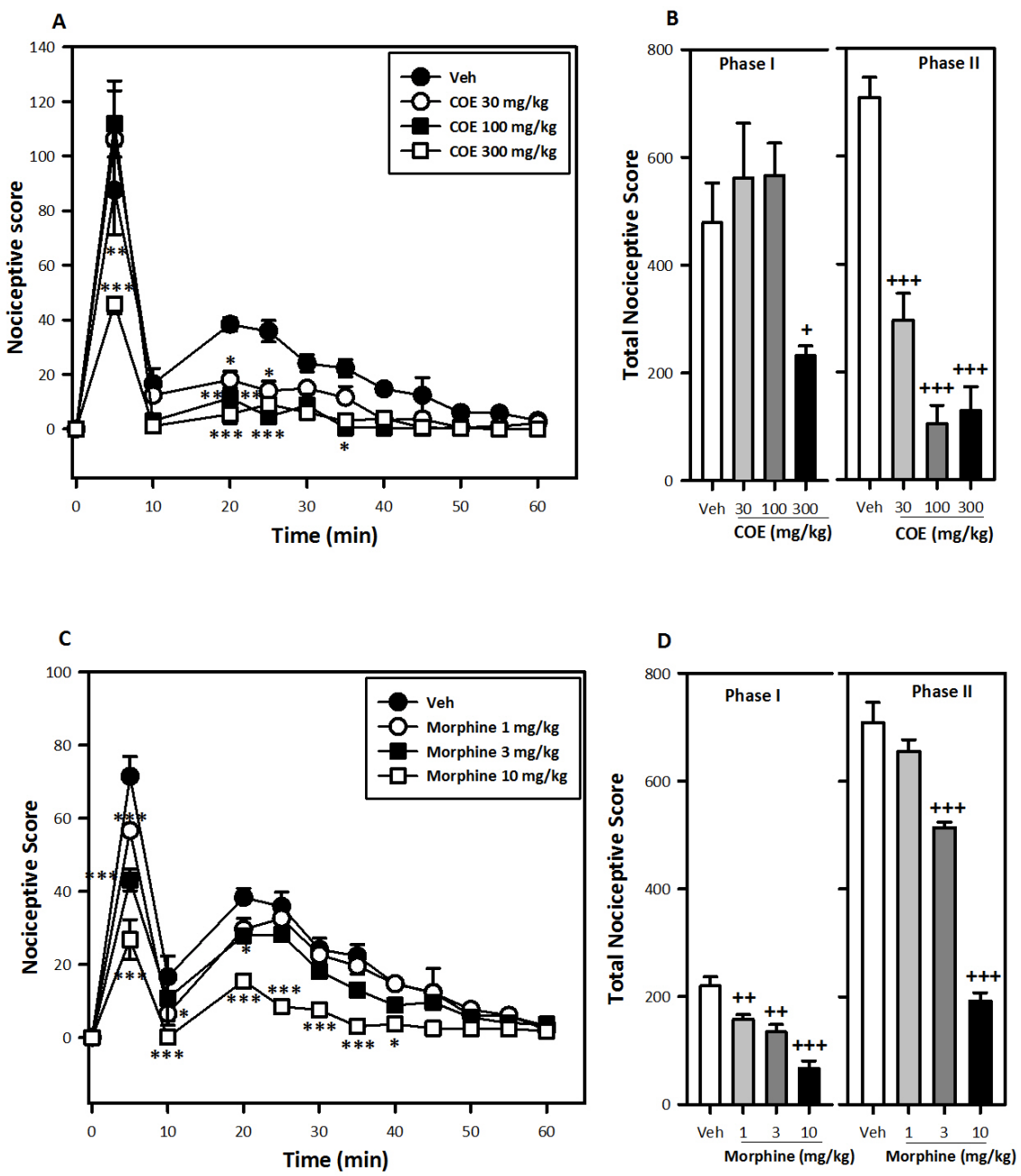

Figure 1: Dose-response effects of COE (30-300 mg/kg, p.o) (A and B) and morphine (1-10 mg/kg, i.p) on formalin-induced nocifensive behaviors in mice. Left panels show the time-course of effects over a 60 min period and the right shows a total nociceptive scores calculated from the AUCs over the first $(0-10 \mathrm{~min})$ and second (10$60 \mathrm{~min}$ ) phases. Nociceptive/pain scores are shown in 5 min time blocks up to $60 \mathrm{~min}$ post formalin injection. Each point represents mean \pm s.e.m $(\mathrm{n}=5)$. $* * * P<0.001 ; * * P<0.01 ; * P<0.05$ compared to vehicle-treated group (Two-way ANOVA followed by Bonferroni's post hoc test). ${ }^{++} P<0.001 ;{ }^{++} P<0.001 ;{ }^{+} P<0.05$ compared to vehicle-treated group (One-way ANOVA followed by Newman-Keul's post hoc test. 

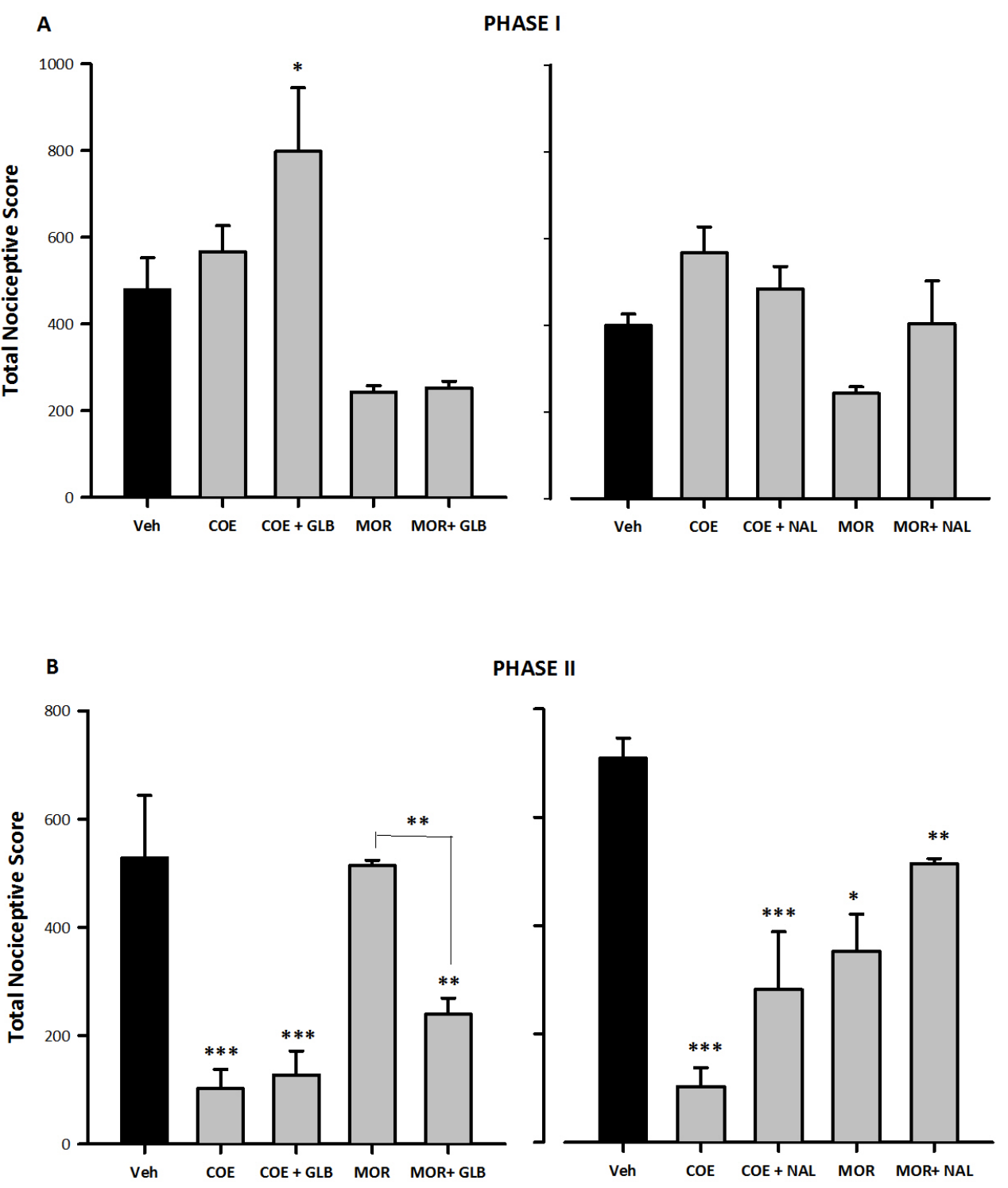

Figure 2: Effects of glibenclamide, GLB ( $8 \mathrm{mgkg}^{-1}$, i.p $)$ and naloxone, NAL ( $2 \mathrm{mgkg}^{-1}$, i.p $)$ on the antinociceptive effects of COE $100 \mathrm{mgkg}^{-1}$, p.o and morphine $3 \mathrm{mgkg}^{-1}$, i.p in the (A) first phase ( upper panel) and (B) second phase ( lower panel). Nociceptive/pain scores are shown in 5 mins time blocks up to 60 min post formalin injection. Each point represents mean \pm s.e.m $(\mathrm{n}=5)$. *** $P<0.001 ; * * P<0.01 ; * P<0.05$ compared to vehicle-treated group (One-way ANOVA followed by Newman-Keul's post hoc test)

\section{DISCUSSION}

This study is a follow up to the work done by Zakaria et al. (2005), who had demonstrated the dose-independent antinociceptive effects of an aqueous extract of $C$. olitorius using the abdominal constriction and hot plate pain models. They had reported that the anti-nociceptive effects of $C$. olitorius was mediated in part through opioid receptor activation. In the present study we evaluated the anti-nociceptive effects of an aqueous leaf extract of $C$. olitorius (COE) using the formalin test and also assessment of the antioxidant activity of COE. In the formalin 
test, there is a distinctive biphasic nociceptive response designated as early and late phases. The early phase also known as neurogenic phase, is as a result of direct stimulation of centrally-linked nociceptors by formalin and it elicits an acute nociceptive behaviour observed as paw licking immediately after the administration of formalin and lasts for 5-10 minutes. The late phase which is purely inflammatory is due to the release of peripheral inflammatory mediators such as histamine, bradykinin, prostaglandins, interleukins, cytokines, chemokines and at least to some degree sensitization of local cells and central nociceptive neurons. There is evidence that suggests that peripheral inflammatory processes are involved in the late phase and are blocked by non-steroidal anti-inflammatory drugs (NSAIDs) while the early phase seems to be unaffected (Zouikr et al., 2013). As evidenced from the results of the present study, COE reduced formalin-induced nociception in both phases of the formalin test similar to morphine, though the effect was not dose-dependent as previously reported by Zakaria et al. (2005).

In order to identify some of the possible mediators involved in the anti-nociceptive effects of COE as a means of elucidating the possible site/mechanism(s) of action, an antagonism study was carried out by using the formalin test. The anti-nociceptive effects of COE and morphine were assessed in the presence of two antagonist drugs (Naloxone and glibenclamide). Each of the two antagonists drugs did not produce antinociception when administered alone. However, prior systemic administration of naloxone (A non- selective opioid receptor antagonist) significantly inhibited antinociceptive effects of COE in the second inflammatory phase and morphine in both phases of formalin test. Opioid receptors are G-protein-coupled receptors (GPCRs) and the main receptors involved in the modulation of pain in mammals. The principal opioid receptor subtypes $\operatorname{mu}(\mu)$, delta $(\delta)$, kappa $(\kappa)$ and nociception /orphanin FQpeptide are all expressed in the spinal cord and in the brain contributing to the modulation of nociceptive transmissions (Pattinson, 2008; Erfanparast et al., 2010). In addition, the $\mu$ and $\kappa$ opioid receptors are also expressed in the enteric nervous system. These four opioid receptors mediate many physiological effects of endogenous opioid systems including pain and analgesia, behaviour, thermoregulation and immunological responses (Bodnar, 2008). T he $\mu$ is the preferred receptor for potent analgesics with high potential for abuse, such as morphine. The present observation with COE strongly indicate that the anti-nociceptive effects of COE is mediated partly through opioidergic receptor activation and that $\mathrm{COE}$ is capable of interrupting the cascade of biochemical events involved in opioid receptor activation to bring about antinociception, since naloxone reversed the antinociception produced by COE.

Our results also demonstrate for the first time that pre-treatment of ICR mice with glibenclamide (A $\mathrm{K}_{\mathrm{ATP}}$-sensitive channel blocker) inhibited the anti-nociceptive effects of COE in the first phase and morphine in the late phase of formalin test. Though in the early phase of formalin test glibenclamide inhibited COE, it however had no effect on the anti-nociceptive effects of morphine, an observation which needs further investigations. Evidently, the anti-nociceptive effects of COE involve the activation of $\mathrm{K}^{+}$ATP-sensitive channel opening and activation. On the basis of structure and specific agonists and antagonists, neural $\mathrm{K}+-$ channels are typically classified into four classes comprising voltage-gated (Kv), calcium- activated $(\mathrm{KCa})$, inward rectifier (Kir) and two-pore (K2P) K+channels (Hajhashemi and Amin, 2011). It has been 
established that central $\mathrm{K}+$-channels especially ATP-sensitive $\mathrm{K}+-$ channels (KATP) of the Kir class are involved in the perception of pain (Ocana et al., 2004). Administration of glibenclamide, an ATPsensitive potassium channel blocker, reversed the anti-nociceptive effects of fluvoxamine and amitriptyline (Hajhashemi and Amin, 2011) whereas drugs that cause the opening of $\mathrm{K}^{+}$channels such as diazoxide, minoxidil, lemakalim and cromakalim, produced antinociception and potentiated analgesic effects such as diazoxide, minoxidil, lemakalim and cromakalim, produced antinociception and potentiated analgesic effects produced by opioid and $\alpha_{2}$ adrenoceptor agonists. Furthermore, central administration of ATP dependent $\mathrm{K}^{+}$-channel blocker, gliquidone, asulfonylurease, reversed the analgesic action of amitriptyline and clomipramine in a hot plate test (Galeotti et al., 2001). It seems that activation of Gprotein coupled receptors by agonists such as $\alpha_{2}$-adrenoceptors, opioids, GABAB, muscarinic $\mathrm{M}_{2}$, adenosine $\mathrm{A}_{1}$, serotonin 5$\mathrm{HT}_{1} \mathrm{~A}$ and cannabinoid and some nonsteroidal anti-inflammatory drugs (NSAIDs) can activate these $\mathrm{K}^{+}$-channels (Ocana et al., 2004). The inhibition of formalin-induced nociception by COE in both the early and late phases strongly suggest that COE can block the activation of actual nociceptors and the release of inflammatory mediators involved in the processing and perception of pain as already established (Erfanparast et al., 2010; Pattinson, 2008).The mechanism of action of COE falls in line with the fact that opioid receptors and $\mathrm{K}^{+}{ }_{\mathrm{ATP}}$-channels converge in regulating release of neurotransmitters, and initiation of neuronal excitability with both signalling pathways being effective in attenuating perception of pain in animals and in patients (Rodrigues and Duarte, 2000).
The anti-nociceptive effects of COE were possibly due to the collective action of all the secondary plant metabolites i.e. phytochemicals present in the extract as shown in Table 1. These phytochemicals were saponins, alkaloids, terpenoids, flavonoids, cardiac glycosides, and anthraquinones perhaps working synergistically to produce anti-nociceptive and antioxidant effects. Triterpenoids and steroidal glycosides, collectively referred to as saponins are bioactive compounds present naturally in many plants. Saponins are a major family of secondary plant metabolites containing a sugar moiety glycosidically linked to a hydrophobic aglycone (sapogenin). Many reports (Sur et al., 2001) had demonstrated the antioxidant and anti-inflammatory pharmacological activities of saponins in both in vitro and in vivo experiments. Similarly, Zhang et al. (2001) had reported the chemoprotective effects of saponins. It was therefore not surprising that COE showed anti-nociceptive effect in the late phase of formalin test since it is purely inflammatory. Flavonoids are polyphenolic compounds that are ubiquitous in nature and are categorized on the basis of their chemical structure, into flavonols, flavones, flavanones, isoflavones, catechins, anthocyanidins and chalcones. The flavonoids have aroused considerable interest recently because of their potential beneficial effects on human health. For instance, they have been reported to have anti-nociceptive (Campelo et al., 2011; Maleki-Dizaji et al., 2008) and antioxidant (Bioportfolio, 2013) effects. Similarly, cardiac glycosides are implicated in the anti-nociceptive and analgesic effects of many medicinal plants (Ugwah-Oguejiofor et al., 2013). Also, anthraquinones, have severally (Ferreira et al., 2004; Masoko et al., 2010) been shown to demonstrate antioxidant activities.

The observed anti-nociceptive effects of COE can also be traced to its antioxidant 
activity secondary to its phytoconstituents. For example, Ratnasooriya et al. (2005) had suggested a link between antioxidant activity and anti-nociception. In this study our results have demonstrated significant antioxidant activity of COE (Table 2) which invariably can be attributable to its saponins, flavonoids, and anthraquinones components (Table 1) as has been shown by previous works (Ferreira et al., 2004; Masoko et al., 2010; Sur et al., 2001). Body cells and tissues are continuously threatened by the damage caused by free radicals and reactive oxygen species, which are produced during normal oxygen metabolism. Reactive oxygen species (ROS) can cause damage to DNA, proteins, and lipids. Antioxidants and dietary fiber are believed to be the principal nutrients responsible for providing protective effects against a variety of diseases, particularly cardiovascular disease and some types of cancer (Grotewold, 2008). The DPPH radical scavenging activity assay assesses the capacity of the extract to reduce or scavenge ROS hence, DPPH spectrophotometric assay method is employed for the investigation of antioxidant activities of natural compounds (Sreedhar et al., 2010). In this study, the percentage antioxidant activity of COE in DPPH was increased in a concentration dependent manner and this compares favorably with the ascorbic acid standard in similar fashion. The DPPH result (Table 2) therefore indicates that $\mathrm{COE}$ possesses antioxidant activity $\left(\mathrm{IC}_{50}=127.15 \mu \mathrm{g} \mathrm{ml}^{-1}\right)$ although lower in potency compared to ascorbic acid $\left(\mathrm{IC}_{50}=7.39 \mu \mathrm{g} \mathrm{ml}^{-1}\right)$. A statement of fact can be made that C. olitorius demonstrated good antioxidant activity and it can be suggested that the plant may be useful in maintaining health and preventing degenerative diseases such as cancer, diabetes, coronary heart disease that are exacerbated by the generation of reactive oxygen species (ROS) in the body.

\section{Conclusion}

The present findings suggest that an aqueous leaf extract of $C$. olitorius (COE) reduced formalin-induced nociception in both the early and late phases in ICR mice and therefore has both central and peripheral antinociceptive effects mediated through opioidergic receptor activation and partly through NO - ${ }_{\mathrm{C}} \mathrm{GMP}$ - ATP - sensitive $\mathrm{K}^{+}$ (NO/CGMP/ATP) - channel pathways. And that $\mathrm{COE}$ has significant antioxidant effect which possibly enhances its antinociceptive effects.

\section{REFERENCES}

Bodnar RJ. 2008. Endogenous opiates and behavior: 2007. Peptide, 29(12): 22922375.

Bioportfolio. 2013. The life science, pharmaceutical and healthcare portal. World News. http://www.ncbi.nih.nih. gov/pubmed/20641059

Campêlo LM, de Almeida AA, de Freitas RL, Cerqueira GS, de Sousa GF, Saldanha GB, Feitosa CM, de Freitas RM. 2011. Antioxidant andantinociceptive effects of Citrus limon essential oil in mice. J. Biomed Biotechnol., 2011: 678673. Doi: 10.1155/2011/678673

Erfanparast A, Tamaddonfard E, Farshid AA, Khalilzadeh E. 2010. Effect of microinjection of histamine into the dorsal hippocampus on the orofacial formalin-induced pain in rats. Eur. $J$. Pharmacol., 627(1-3):119-123.

Ferreira MA, Nunes OD, Fontenele JB, Pessoa OD, Lemos TL, Viana GS. 2004. Analgesic and anti-inflammatory activities of a fraction rich in oncocalyxone A isolated from Auxemmaoncocalyx. Phytomedicine, 11(4): 315-322.

Galeotti N, Ghelardini C, Bartolini A. 2001. Involvement of potassium channels in 
amitriptyline and clomipramine analgesia. Neuropharmacology, 40(1): 75-84.

Grotewold E. 2008. The Science of Flavonoids. Springer Science: New York

Hajhashemi V, Amin B. 2011. Effect of glibenclamide on anti-nociceptive effects of antidepressants of different classes. Clinics (Sao Paulo), 66(2): 321-325.

Hayashida K, Takeuchi T, Shimizu H, Ando K, Harada E. 2003. Lactoferrin enhances opoid-mediated analgesis via nitric oxide in the rat spinal cord. Am. J. Physiol. Regul. Integr. Comp. Physiol., 285: R312.

Khanavi M, Mohammad-reza D, Nikoui V, Sattar Ostadhadi S, Bakhtiarian A. 2012.

Evaluation of Analgesic Effects of Hydroalcoholic Extract of Marrubium parviflorum by Formalin Test in Mice. Asian Journal of Plant Sciences, 11: 9699.

Le Bars D, Gozariu M, Cadden SW. 2001. Animal models of nociception. Pharmacol. Rev., 53(4): 597-652.

Maleki-Dizaji N, Nazemiyeh H, Maddah N, Mehmani F, Garjani A. 2008. Screening of extracts and fractions from aerial parts of Stachys schtschegleevii Sosn. for antiinflammatory activities. Pak. J. Pharm. Sci., 21(4): 338-343.

Masoko P, Gololo SS, Masoko P, Eloff JN, Howard RI, Mampruru LJ. 2010. Evaluation of the antioxidant, antibacterial, and antiproliferative activities of the acetone extract of the roots of Sennaitalica (Fabaceae). Afr J Tradit Complement Altern Med., 7(2): 138-148.

Ocana M, Cendan CM, Cobos EJ, Entrena JM, Baeyens JM. 2004. Potassium channels and pain: present realities and future opportunities. Eur. J. Pharmacol., 500(1-3): 203-219.

Pattinson KT, Rogers R, Mayhew SD, MacIntosh BJ, Lee MC, Wise RG. 2008. Remifentanil-induced cerebral blood flow effects in normal humans: dose and ApoE genotype. AnesthAnalg, 106(1): 347.

Prashant Tiwari P, Kumar B, Kaur M, Kaur G, Kaur H. 2011. Phytochemical screening and Extraction: A Review. Internationale Pharmaceutica Sciencia, 1(1): 98-106.

Ratnasooriya WD, Deraniyagala SA, Bathige SD, Goonasekara CL, Jayakody JR. 2005. Antinociceptive action of aqueous extract of the leaves of Ixoracoccinea. Acta Biol Hung, 56(1-2): 21-34.

Rodrigues AR, Duarte ID. 2000. The peripheral antinociceptive effect induced by morphine is associated with ATPsensitive $\mathrm{K}(+)$ channels. $\mathrm{Br} \quad J$. Pharmacol., 129(1): 110-114.

Ronald L. Prior, Xianli Wu, Karen Schaich. 2005. Standardized Methods for the Determination of Antioxidant Capacity and Phenolics in Foods and Dietary Supplements J. Agric. Food Chem., 53, 4290-4302.

Sreedhar V, Ravindra LK, Gopal NM, Nath MS. 2010. In vitro antioxidant activity and free radical scavenging potential of roots of Vitex trifoliate. Res. J. Pharm., Biol. Chem. Sci., 1(4): 1036-1044.

Stankovic MS, Niciforovic N, Mihailovic V, Topuzovic M, Solujic S. 2010. Antioxidant activity, total phenolic content and flavonoid concentrations of different plant parts of Teucrium $L$. Subsp. Polium. Acta Societatis Botanicorum Poloniae, 81(2): 117-122.

Sur P, Chaudhuri T, Vedasiromoni JR, Gomes A, Ganguly DK. 2001. Antiinflammatory and antioxidant property of Saponins of tea [Camellia sinensis (L) O. Kuntze] root extract. Phytother Res., 15(2): 174-176.

Ugwah-Oguejiofor CJ, Abubakar K, Ugwah MO, Njan AA. 2013. Evaluation of the antinociceptive and anti-inflammatory 
effect of Caralluma dalzielii. Journal of Ethnopharmacology, 150: 967-972.

Vasconcelos SMM, Oliveira GR, DeCarvalho MM, Rodrigues ACP, Silveira ER. 2003. Antinociceptive activities of the hydroalcoholic extracts from Erythrinna veltina and Erythrina mulungu in mice. Biol. Pharm. Bull., 26: 946-949.

Vissers K, Hoffmann V, Geenen F, Biermans R, Meert T. 2003. Is the second phase of the formalin test useful to predict activity in chronic constriction injury models? A pharmalogical comparison in different species. Pain Practice, 3: 398-309.

Zakaria ZA, Somchit MN, Zaiton, H, Mat-Jais AM, Suleiman MR, Farah W, Nazaratul-

Marawana R, Fatimah CA. 2006. The invitro antibacterial activity of Corchorous olitorius extracts. Int. J. Pharmacol., 2(2) 213-215.
Zeghichi SS, Kallithkara, Simopoulos AP. 2003. Nutritional composition of molehiya (Corchorus olitorius) and Stamnagathi (Cichorium spinosum). In Plants in Human Health and Nutrition Policy, Simopoulus AP, Gopalan C (eds). Karger: Basel; 1-21.

Zhang CF, Sun QS, Wang ZT, Chou GX. 2001. Studies on constituents of the leaves of Lindera aggregata (Sims) Kosterm. Zhongguo Zhong Yao ZaZhi, 26(11): 765-767.

Zouikr I, Tadros MA, Clifton VL, Beagley KW, Hodgson DM. 2013. Low formalin concentrations induce fine-tuned responses that are sex and age-dependent: A developmental study. PLoS One, 8(1): e53384. 